\title{
Childhood obesity: research as a springboard for physical activity policies
}

\author{
Shale L. Wong' ${ }^{1}$, Paul J. Chung ${ }^{2,3,4}$; and the Pediatric Policy Council
}

T he Pediatric Policy Council is a federal child health policy consortium representing four major pediatric academic groups (Academic Pediatric Association, American Pediatric Society, Association of Medical School Pediatric Department Chairs, and Society for Pediatric Research). Working in partnership with the American Academy of Pediatrics Department of Federal Affairs, our mission is to inform the development and implementation of federal legislation and policies related to both the health of children and the academic pediatric providers and institutions that serve them. For many of the readers of this journal, we are YOUR federal child health policy advocacy organization.

We are pleased to announce a new regularly recurring feature in this journal. We have been invited to submit a short commentary on child health policy concerns related to one (or more than one) article in each issue. Each commentary will be led by an author with policy expertise in the relevant field, who will use the article as a springboard to update readers on the federal policy landscape and potential opportunities for advocacy. For this inaugural commentary, Shale Wong and Paul Chung will discuss the selected article by Bruyndonckx et al., "Childhood Obesity Related Endothelial Dysfunction: An Update on Pathophysiological Mechanisms and Diagnostic Advancements" (1).

Because of the prevalence of childhood obesity and the complex, pervasive nature of its effects on lifelong health, social and environmental policy interventions must be considered a core component of its prevention and management (2). Policy approaches to affect nutrition, activity, and environmental influences are broad-ranging and include dietary guidelines for school nutrition (e.g., the Healthy Hunger-Free Kids' Act); food and beverage taxes; improving access to healthy affordable foods; limiting marketing to children; expanding access to safe streets and parks; and building physical activity into, before and after the school day. In Bruyndonckx's article on endothelial dysfunction, the authors suggest that physical activity is particularly critical during windows of life when endothelial cells appear most reactive and affected by sedentary behavior, with effects that may vary widely by frequency, intensity, and duration (1). In addition, they point to intriguing evidence regarding the effect of postnatal psychological stress, which may add to our understanding of the long-term consequences of adverse childhood experiences. These are data that could inform policy development and strengthen support for interventions that promote childhood health and health behaviors to limit further development of chronic disease. As we better understand how cellular mechanisms for atherosclerosis begin in childhood, it becomes increasingly imperative to begin translating that knowledge into social and environmental policy actions that can prevent or interrupt progression of pathophysiology. Supporting research both on the childhood mechanisms of adult disease and on the translation of knowledge into practices and policies is itself a critical policy priority.

With respect to biological mechanisms, support and effort directed toward understanding the widespread molecular effects of obesity are critical. For instance, the epigenetic sequelae of obesity are poorly understood and are likely of major importance with respect to not only carriage of effects from childhood to adulthood but also transmission of obesity and its effects across generations.

With respect to translation, pediatricians have a critical responsibility, albeit limited opportunity, to affect children's activity. The promotion of physical activity is an essential component of primary and preventive care. On an individual basis, screening for number of minutes of daily physical activity and encouraging moderate to vigorous activity for $60 \mathrm{~min}$ daily follows guidelines established by the US Department of Health and Human Services and endorsed by the American Academy of Pediatrics, American Heart Association and prominent medical organizations. The second edition of the physical activity guidelines is expected to be released in 2018 following a revision process that begins this year. The development of early markers of cardiovascular disease, such as endothelial dysfunction, may ultimately help us develop more nuanced and powerful guidance than our current recommendations provide.

Establishing environmental conditions that allow safe physical activity and facilitate active living changes the baseline for entire populations of children rather than focusing on one child at a time. From a policy perspective, these levers are relevant at the Federal, state and local levels. Federal

\footnotetext{
'Department of Pediatrics, Children's Hospital, University of Colorado School of Medicine, Aurora, Colorado; ${ }^{2}$ Department of Pediatrics, University of California, Los Angeles, Los Angeles, California; ${ }^{3}$ Department of Health Policy \& Management, University of California, Los Angeles, Los Angeles, California; ${ }^{4}$ RAND Health, The RAND Corporation, Santa Monica, California. Correspondence: Paul J. Chung (PaulChung@mednet.ucla.edu) 


\section{Childhood obesity Commentary}

policies to increase physical activity primarily focus on interventions to address safety and access to active transportation and recreation. While safety may address lighting or refurbishing streets, parks and creating bike lanes, access includes such issues as increasing opportunities for activity during the school day. Legislation passed and reauthorized in 2015 includes funding for Safe Routes to School through the FAST Act (Fixing America's Surface Transportation Act) (3) and funding in support of health and physical education via Title IV block grants in the Every Student Succeeds Act (previously known as the Elementary and Secondary Education Act) (4). Implementation of these laws lies with the states where efforts are further strengthened at the state or district level. It is at the local level, particularly in schools, where most attempts are made to strengthen wellness policies and increase physical education, recess and total time committed to activity. Policy actions such as these are meeting varying degrees of success in different states. For example, in Colorado, the state legislature passed a requirement that elementary schools provide opportunity for $150 \mathrm{~min}$ of physical activity during the school week. There is no state currently that mandates $60 \mathrm{~min}$ of daily physical education during school for grades K-12. However, this is a specific focus that the American Academy of Pediatrics is highlighting for state advocacy efforts (5).

Pediatricians, researchers, and health care providers can improve the outcomes of children in their communities by sharing data and expertise in ways that are new to policy makers and the people they serve. Advocating for policies that create environments more conducive to increased activity that can then diminish cellular changes that lead to heart disease illustrates a pathway that is not intrinsically obvious to a policy maker or community leader and might be compelling. As we identify these connections between medical science and social well-being, we can inform decision making that will improve population health outcomes across the lifespan.

\section{ACKNOWLEDGMENTS}

Members of the Pediatric Policy Council include Vivek Balasubramaniam, MD; Cynthia Bearer, MD, PhD; Paul J. Chung, MD, MS; Stephen Daniels, MD, PhD; Scott C. Denne, MD; Jean L. Raphael, MD, MPH; Scott Rivkees, MD; Shetal Shah, MD; and Shale L. Wong, MD, MPH.

\section{STATEMENT OF FINANCIAL SUPPORT}

The work of the Pediatric Policy Council is funded by its member organizations (Academic Pediatric Association, American Pediatric Society, Association of Medical School Pediatric Department Chairs, and Society for Pediatric Research) and the American Academy of Pediatrics.

Disclosures: There are no conflicts of interest or disclosures.

\section{REFERENCES}

1. Bruyndonckx L, Hoymans VY, Lemmens K, Ramet J, Vrints CJ. Childhood obesity related endothelial dysfunction: an update on pathophysiological mechanisms and diagnostic advancements. Ped Res this issue.

2. Campbell MK. Biological, environmental, and social influences on childhood obesity. Pediatr Res 2016;79:205-11.

3. Fixing America’s Surface Transportation Act. Public law 114-94, 4 December 2015.

4. Every Student Succeeds Act. Public law 114-95, 10 December, 2015.

5. State advocacy focus: school physical education and activity. In: State Government Affairs: State Legislation Report, 2015. Elk Grove Village, IL: American Academy of Pediatrics; 2015:43. https://www.aap.org/en-us/ advocacy-and-policy/state-advocacy/Documents/2015SLRFINAL_Web. pdf. Accessed 2 February 2016. 